\title{
Measuring the readability of Indonesian biomass websites: The ease of understanding biomass energy information on websites in the Indonesian language
}

\author{
Muhammad Kunta Biddinika ${ }^{a, *}$, Retno Puji Lestari ${ }^{\mathrm{b}}$, Bayu Indrawan ${ }^{\mathrm{c}}$, Kunio Yoshikawa ${ }^{\mathrm{a}}$, \\ Koji Tokimatsu ${ }^{a}$, Fumitake Takahashi ${ }^{\text {a }}$ \\ ${ }^{a}$ Department of Environmental Science and Technology, Interdisciplinary Graduate School of Science and Engineering, Tokyo Institute of Technology, \\ 4259 Nagatsuta-cho, Midori-ku, Yokohama 226-8503, Kanagawa, Japan \\ b Tokyo Indonesian School, 4-6-6 Meguro, Meguro-ku, Tokyo 153-0063, Japan \\ ' Surya University, Gd 01 Scientia Business Park, Jl. Boulevard Gading Serpong O/1 Summarecon, Serpong 15810, Indonesia
}

\section{A R T I C L E I N F O}

\section{Article history:}

Received 22 November 2014

Received in revised form

26 August 2015

Accepted 13 January 2016

Available online 30 January 2016

Keywords:

Internet

Indonesia

Biomass information

Website

Energy education

\begin{abstract}
A B S T R A C T
Renewable energy-related information in the Indonesian language (Bahasa Indonesia) is nowadays easily accessible on the internet and seeking information from the internet has become the second highest activity of Indonesian netizens. This paper aims to examine the readability of biomass energy-related information that is retrieved from the internet and available in the Indonesian language. By using Google ${ }^{\mathbb{R}}$ Indonesia's search results of four keywords on biomass renewable energy in the Indonesian language, educational materials on biomass energy were examined. Some inclusion and exclusion criteria have been applied among the search results in order to discriminate the educational materials among the results for further readability assessment by employing four readability standard formulas (SMOG, Gunning Fog, Flesch-Kincaid, and Dwiyanto Djoko Pranowo's). The results showed that information on biomass energy is still difficult to understand by the general public. The results may also become a success indicator of biomass energy campaigns as well as renewable energy education in Indonesia as a key role for its implementation in the near future. This study also contributes to the information quality assessment framework to languages other than English since internet technology has made information in any language accessible.
\end{abstract}

\section{Contents}

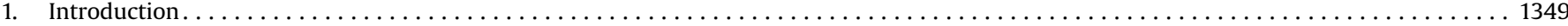

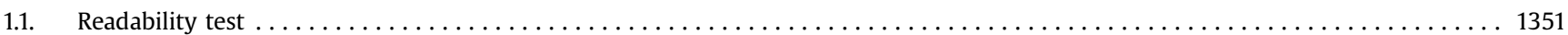

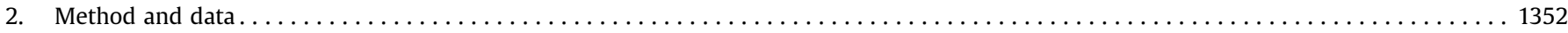

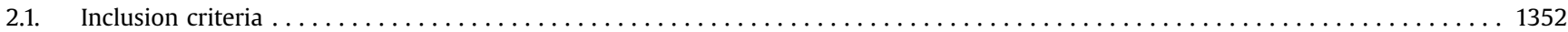

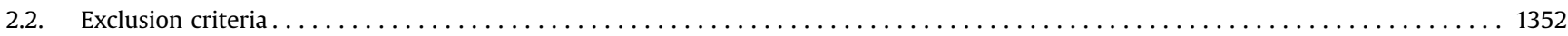

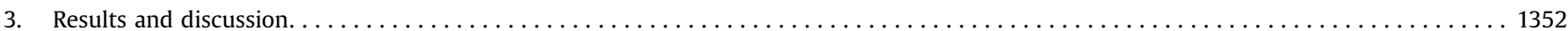

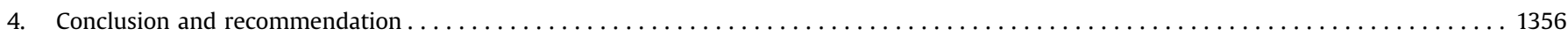

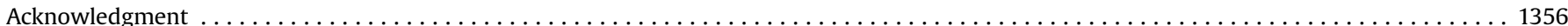

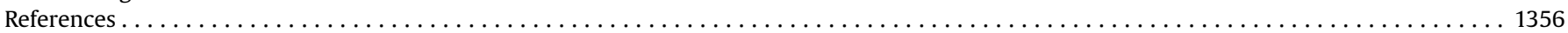

\footnotetext{
* Corresponding author.

E-mail addresses: mkuntab@gmail.com, kunta.m.aa@m.titech.ac.jp (M.K. Biddinika).
}

\section{Introduction}

The internet has now become one of the most important sources of information. The growing capability of mobile internet connections along with the shrinking size of hardware, from computer desktops to mobile phones - so-called smartphones, the general public nowadays 
can easily seek information from the internet as it is basically at their fingertips.

A wide variety of information regarding renewable energy is now available on the internet; however, studies regarding renewable energy information are still limited. Although some previous studies suggested that information about renewable energy plays an important role in the general public's acceptance of it due to its influence on the general public's knowledge of energy technology [1-6], to the best of the author's knowledge, there is still no study on the ease with which the information can be read and understood, known as the 'readability' of biomass renewable energy information that is available on the internet.

Indonesia, which is said to be one of the wealthiest biomass countries, still has a fairly low-utilization of its biomass potential $[7,8]$. The biomass potential in Indonesia mainly comes from rice residues (rice husks) and palm oil residues since Indonesia is the world's third largest rice producer as well as rice consumer and the world's largest palm oil producer [7,9]. One of the reasons why the utilization of renewable energy in Indonesia is still low, especially from biomass sources, is because biomass energy information remains sparse. Renewable energy information plays an important role in its successful implementation as it has been reviewed comprehensively in recent literature studies on the social acceptance of renewable energy sources by a contingent valuation method [10]. Some recent studies on renewable energy implementation show that renewable energy information still remains as one of the barriers. In the United States of America, a dearth of high-quality information about renewable electricity technologies was found to be one of the impediments of renewable energy in the USA [11]. In Malaysia, a neighboring country to Indonesia, there is an understanding gap on renewable marine energy information especially between policymakers, investors, and the general public, which has become a barrier to push the technology forward [12]. In India, the adoption of renewable energy still faces some barriers related to its information, such as the lack of a formal information channel on renewable energy for small and mediumscale enterprises, poor access to renewable energy information compared with conventional energy technologies, lack of easy access to information about the latest renewable energy technologies, as well as the general public's preference to take their friends' advice rather than obtain information from experts [13]. In Indonesia, biomass information in the Indonesian language may also be difficult to understand, which, in turn, is influencing the Indonesian people's knowledge on renewable energy.

From the viewpoint of an information source, Indonesians are among the largest users of the internet as an information source in the world and the number of internet users in Indonesia has grown dramatically this decade [14]. The most recent demography of internet users in Indonesia is based on a survey by the Indonesian Internet Service Provider Association (APJII) in 2014 on 2000 internet users located in both rural and urban areas [15]. Most of the internet users in Indonesia are young people with a high-school educational background as shown in Figs. 1 and 2. Almost fifty percent of internet users in Indonesia are aged between 18 and 25 years old who have graduated from senior high-school only. This means that they have not pursued their education to a higher level by attending a college, a vocational school, or a university to obtain a bachelor's degree or as a postgraduate. This education profile of internet users is consistent throughout every province in Indonesia for both rural and urban areas. By daily activities, internet users in Indonesia can be divided into three groups as shown in Fig. 3. The first group is the largest group comprising of employees and those who are self-employed with their own businesses (entrepreneurs), which consists of $55 \%$ of the survey sample. The second group is the next largest group comprising of university students and housewives, which consist of $18 \%$ and $16 \%$ of the sample, respectively. The third group is the smallest group comprising of high school and elementary school students (5\%) and the

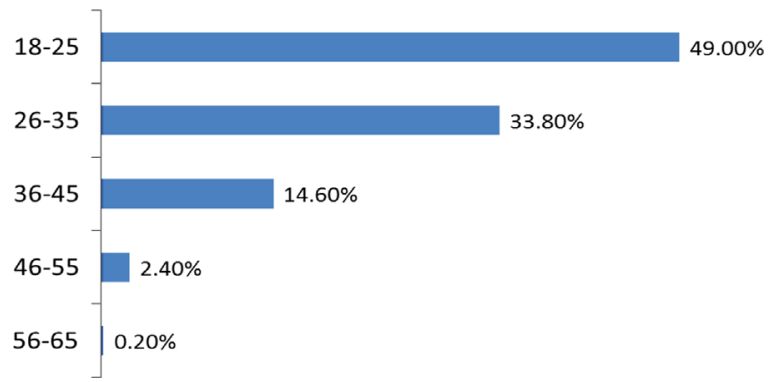

Fig. 1. Profile of internet users in Indonesia by age based on 2014's survey [15].

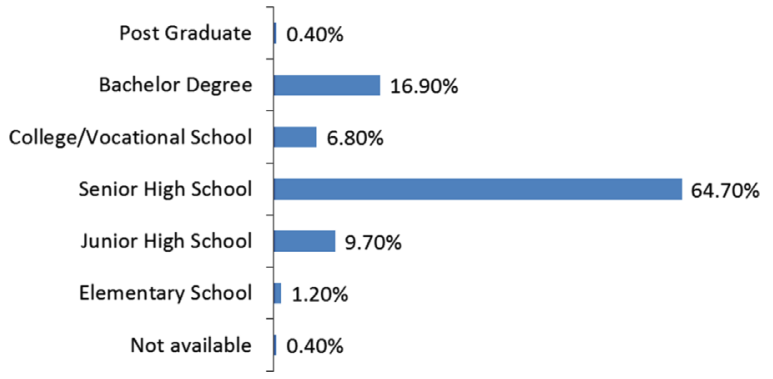

Fig. 2. Profile of internet users in Indonesia by their educational background based on 2014's survey [15].

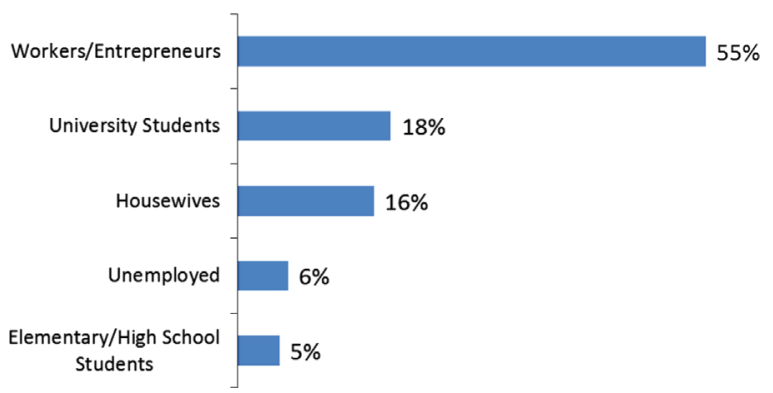

Fig. 3. Profile of internet users in Indonesia by their daily activity based on 2014's survey [15].

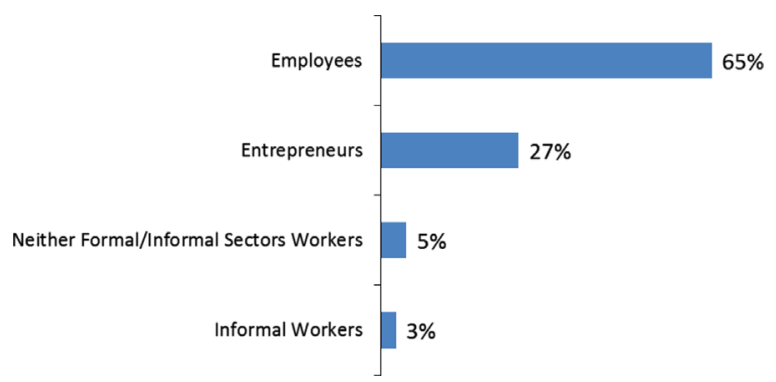

Fig. 4. Profile of internet users in Indonesia by their occupation based on 2014's survey [15].

unemployed (6\%). By occupation as shown in Fig. 4, most of the internet users in Indonesia are employees (65\%), those who are selfemployed or entrepreneurs (27\%), a small number of informal workers (3\%) and people who are neither formal nor informal sector workers (5\%).

In terms of demography, the target readers of renewable energy information should be clarified so that information can be well prepared especially by the ease with which information can be read and understood. Therefore, the term, "general public" used in this study refers to most of the categories shown in the aforementioned internet user profile. To our knowledge, there is still no current study focusing 
on biomass energy information in the Indonesian language available on the internet.

The usefulness of the information, including biomass energyrelated information, depends upon a person's readability and understandability [8]. Therefore, this study aims to discuss whether the biomass renewable energy information on the Indonesian websites is easy or not to understand by using a readability measurement method. Four readability scoring standards have been applied to this study in order to assess how easy it is to understand biomass energy information in the Indonesian language, which is available on the internet.

\subsection{Readability test}

Readability is the starting point for the comprehension of a text [16]. Therefore, the readability tests have all been designed to provide a quantifiable assessment of how easy the information text is to read [17]. If the text is written at a higher level than the reading skills of the target audience, the target audience will most likely not understand the text, and, in turn, the message will not be appropriately conveyed to them [18].

Previous studies have shown that readability measurements are being used for the improvement of communicating health information, such as the supporting information sought by a patient on the internet [19-21], as well as for corporate and investor relations since previous works have found a relationship between the readability of Corporate Social Responsibility (CSR) communications and a company's performance [8], the relationship between the readability of an annual report and a company's performance besides its earning persistence [22], and the adoption and application of occupational health and safety (OHS) by measuring the readability of its guidance documents [16]. An intriguing study involving readability has also been done on the expert-non-expert communications about complex science information, such as DNA evidence reports in the criminal justice system, where forensic experts need to communicate with police, lawyers, prosecutors, and judges from law enforcement agencies who are not always familiar with DNA reports [23]. Readability has also become an issue in the improvement of education by examining learning textbooks in language teaching [24].

Although the readability issue was originally an English-based concern as indicated by most of the aforementioned studies, it has later become universally applicable to non-English languages, such as Finnish, Hungarian, Malaysian, Spanish, possibly Turkish [16] and Indonesian (Bahasa Indonesia) [25].

There are at least 10 (ten) readability measurement methods, as Vargas et al. collected, which have then been used for studying the readability of online materials on breast cancer treatment for patients [21]. These ten methods are Coleman-Liau, Flesch-Kincaid, Flesch Reading Ease, FORCAST, Fry Graph, Gunning Fog, New Dale-Chall, New Fog Count, Raygor Estimate, and the Simple Measure of Gobbledygook (SMOG).

This study utilized four readability indicators, three of them are among the aforementioned formulas and have been widely used for English-based texts, and one indicator has been applied to Indonesian text only, namely the Djoko Formula. This study selected only three English-based formulae due to time limitations. Moreover, since the observed texts were in the Indonesian language, the Djoko Formula, as it was specifically designed for the Indonesian language, became the most focused formula in this study. Among the English-based formulae, this study chose SMOG, Gunning-Fog, and Flesch-Kincaid due to the advantage of their simple calculations and interpretations rather than their popularities among the others in the readability study [26]. These three formulae were also found within the most recent literature on readability studies. A search attempt was conducted on Google Scholar using the keyword, "readability" in August, 2015. A hundred search results were collected for references published since 2011 and sorted by their relevance to the "readability" term. The readability formulae taken from the research methodologies of the references were collected and the results are shown in Table 1 . Since the Flesch-Kincaid Formula is very similar to the Flesch Formula, this study chose the Flesch-Kincaid Formula rather than the Flesch Formula as it has been more frequently used in the references. The formula of each of the three English-based indicators in this study is presented in Table 2.

The SMOG (Simple Measure of Gobbledygook) index is a readability formula that estimates the level of education needed to understand a piece of writing. This index is being widely used for checking consumer-oriented healthcare materials.

The Gunning Fog index is a measure of text readability based on a sentence's length and the hard-to-understand words in that sentence. A text with an index of 7-8 is considered an easy-tounderstand text, while a text with an index of above 12 is considered too hard to read for most people [20].

The Flesch-Kincaid Grade Level test uses word lengths and sentence lengths. The result is a number that corresponds to a school grade level, which means that a higher score corresponds to a higher level of education that is needed to understand the text. This index is widely used by the United States Army for assessing technical manuals [27].

The Djoko Formula is a readability formula for Indonesian texts that was developed by Professor Dwiyanto Djoko Pranowo of Literature Study at Yogyakarta State University, Indonesia [28]. To the author's knowledge, there is still no other readability formula that has been developed specifically for the Indonesian language except the one developed by Djoko. The Djoko Formula measures whether an Indonesian text is easy to read or not based on 13 (thirteen) indicators, which are the number of paragraphs, the number of sentences in each paragraph, the length of a sentence, complex (compound) sentences, passive sentences, extension sentences, sentences with polysemy words, abstract words, unfamiliar words, loan words, terms, conjunctions, and idioms (phrases) [28]. The indicators of the Djoko Formula and its score are presented in more detail in Table 3 as it is less accessible than other originally English-based formulas.

Each indicator has three quantifiable readability criteria that represent the level of ease to read a certain text. Each indicator is scored based on the criteria compliance so that its contribution to the

Table 1

Number of references using the readability index in a hundred Google Scholar search results.

\begin{tabular}{ll}
\hline Readability index & Number of references \\
\hline Flesch-Kincaid grade level & 47 \\
Flesch reading ease & 38 \\
Gunning-Fog index & 31 \\
SMOG index & 29 \\
FORCAST & 11 \\
Fry graph & 9 \\
New Dale-Chall & 8 \\
Coleman-Liau & 8 \\
Raygor estimate & 7 \\
New Fog count & 6 \\
\hline
\end{tabular}

Table 2

Three calculation methods of readability indices used in this study [18].

\begin{tabular}{ll}
\hline Index & Formula \\
\hline SMOG index & $\begin{array}{l}3+\text { square root of polysyllable }^{\mathrm{a}} \text { counts per 30 sentences } \\
\text { Gunning Fog index } \\
\left.\text { words }{ }^{\mathrm{a}}\right)\end{array}$ \\
$\begin{array}{l}(0.39 \times \text { average number of words per sentence })+ \\
\text { Flesch-Kincaid }\end{array}$ & $(11.8 \times$ average number of syllables per word $)-15.59$ \\
\hline
\end{tabular}

a Words with three or more syllables. 
readability of a certain text can be measured. The score of each indicator is then summarized in order to obtain the Djoko Formula score of a text. The text is considered as easy, medium, and hard to understand if the score ranges from 13-21.7, 21.8-30.5, and 30.6-39, respectively [28].

\section{Method and data}

An internet information search was performed in the second and third week of October, 2014 by using Google ${ }^{\circledR}$ Indonesia's search engine for the following terms/keywords in the Indonesian language; energi biomassa, biomassa, energi terbarukan biomassa, tenaga biomassa, which can be translated into English as biomass energy, biomass, renewable energy of biomass, and biomass power, respectively.

The first 10 consecutive Google ${ }^{\circledR}$ result pages were selected, resulting in a total of 100 websites being obtained from each keyword for further screening since 10 search results appeared from each search result page on Google ${ }^{\circledR}$. The screening of a hundred web-based texts was based on the following criteria:

\subsection{Inclusion criteria}

Texts found on any website containing education materials on renewable biomass energy and written in the Indonesian language for further analysis.

\subsection{Exclusion criteria}

Texts found on any renewable biomass energy websites requiring a subscription or membership, or websites designed for commercial purposes were excluded. Moreover, any texts consisting of less than 200 words on biomass information websites found in the search results were also excluded due to their lack of information. This study also excluded texts found on websites for news outlets, blogs, social media, book chapters available through Google ${ }^{\circledR}$ Books, presentations and writings from file-sharing and repository websites, such as slideshare, academia, scribd, and prezi, etc.

The distinction between information or education material on renewable energy of biomass versus material for commercial purposes was made by screening the content of those websites. In addition, the publisher or owner of the website where the measured text located was categorized as follows; universities, community or non-profit organizations, government bodies which were categorized into government agencies as government organizations in general and governmental research and development agencies, businesses, and individual owners or publishers. By this categorization, the information source can be traced down for deeper analysis.

\section{Results and discussion}

From the searching of each keyword, the lowest number of words of a keyword resulted in the most obtained website links of the texts. The keyword biomassa generated 8,750,000 search results, while energi biomassa, tenaga biomassa, and energi terbarukan biomassa generated $388,000,184,000$, and 65,700 search results, respectively. The first 100 consecutive results were selected from each keyword resulting in a total of 400 search results. Of these, 381 were excluded from further analysis due to the exclusion criteria, duplication, and language being non-Indonesian. Most of the excluded results were renewable energy news broadcasted by online news portals and reposted by other websites including blogs and social media.
Table 3

Indicators and scores of the Indonesian readability index [28].

\begin{tabular}{|c|c|c|c|}
\hline Indicator no. & Indicator & Criteria & Score \\
\hline 1 & Average number of paragraphs & $\begin{array}{l}\leq 5 \\
6 \\
\geq 7\end{array}$ & $\begin{array}{l}1 \\
2 \\
3\end{array}$ \\
\hline 2 & $\begin{array}{l}\text { Average number of sentences per } \\
\text { paragraph }\end{array}$ & $\begin{array}{l}6.0-7.1 \\
4.7-5.9 \\
3.6-4.6\end{array}$ & $\begin{array}{l}1 \\
2 \\
3\end{array}$ \\
\hline 3 & Length of a sentence & $\begin{array}{l}7.2-8.5 \\
8.6-9.8 \\
9.9-11\end{array}$ & $\begin{array}{l}1 \\
2 \\
3\end{array}$ \\
\hline 4 & Percentage of extension sentences & $\begin{array}{l}79.0-85.6 \% \\
85.7-92.4 \% \\
92.3-99 \%\end{array}$ & $\begin{array}{l}1 \\
2 \\
3\end{array}$ \\
\hline 5 & Percentage of compound sentences & $\begin{array}{l}38-42 \% \\
43-46 \% \\
47-50 \%\end{array}$ & $\begin{array}{l}1 \\
2 \\
3\end{array}$ \\
\hline 6 & Percentage of sentences with polysemy & $\begin{array}{l}44.2-56.3 \% \\
32.1-44.1 \% \\
19.9-32 \%\end{array}$ & $\begin{array}{l}1 \\
2 \\
3\end{array}$ \\
\hline 7 & Percentage of passive sentences & $\begin{array}{l}11.3-17.7 \% \\
17.8-24.1 \% \\
24.2-30.5 \%\end{array}$ & $\begin{array}{l}1 \\
2 \\
3\end{array}$ \\
\hline 8 & Percentage of unfamiliar words & $\begin{array}{l}7.5-11.6 \% \\
11.7-15.7 \% \\
15.8-19.7 \%\end{array}$ & $\begin{array}{l}1 \\
2 \\
3\end{array}$ \\
\hline 9 & Percentage of abstract words & $\begin{array}{l}15-20.7 \% \\
20.8-26.4 \% \\
26.5-32.2 \%\end{array}$ & $\begin{array}{l}1 \\
2 \\
3\end{array}$ \\
\hline 10 & Percentage of terms & $\begin{array}{l}1.4-4.7 \% \\
4.8-8.1 \% \\
8.2-11.4 \%\end{array}$ & $\begin{array}{l}1 \\
2 \\
3\end{array}$ \\
\hline 11 & Percentage of conjunctions & $\begin{array}{l}3-4.4 \% \\
4.5-5.9 \% \\
6-7.3 \%\end{array}$ & $\begin{array}{l}1 \\
2 \\
3\end{array}$ \\
\hline 12 & Percentage of loan words & $\begin{array}{l}1.7-2.7 \% \\
2.8-4.8 \% \\
4.9-7.8 \%\end{array}$ & $\begin{array}{l}1 \\
2 \\
3\end{array}$ \\
\hline 13 & Percentage of phrases & $\begin{array}{l}2.2-3.1 \% \\
3.2-4 \% \\
4.1-4.9 \%\end{array}$ & $\begin{array}{l}1 \\
2 \\
3\end{array}$ \\
\hline
\end{tabular}

Legend: score of indicator; 1 =easy, $2=$ medium, 3 =hard.

Therefore, content duplication was frequently found in websites owned by the government and research agencies as well as by universities.

Instead of merely rewriting and then reposting the materials created originally rather than from their work, the government bodies, research agencies, and universities should take a more important role in initiating the dissemination of information on renewable energy technologies because of their duties and functions. Although sharing online information, especially media portal news is becoming an increasingly growing phenomena nowadays, and, as indicated in the 
recent studies [29], especially because previous studies have revealed that news sharing may establish social relationships, reputations, and facilitate social interaction and group discussions [30-32]. There needs to be a responsibility to take more of a key role as a content-creator rather than as a content-disseminator on renewable energy socialization.

The dissemination of information, especially renewable energy was crucial for the implementation of renewable energy as some practices in Malaysia, India, and the United States of America found it particularly difficult to obtain information and knowledge on renewable energy technologies so that it contributed to obstacles to renewable energy implementation [10-13]. It is not only how to create a credible and reliable information source, but also how to spread it to the general public, because the information possessed by the general public, that is not limited to some individuals, becomes the foundation of their resulting behavior [10]. The more individuals are reached by the information, the more the information becomes diffused publicly. In the case of India, the lack of reliable information was found to be a barrier to the adoption of renewable energy. Therefore, it is important for scientists and engineers working on renewable energy technologies to engage with the public more frequently for the most effective dissemination of renewable energy information. The information from scientists and engineers is considered to be reliable information about renewable energy technologies.

Although Google ${ }^{\circledR}$ Indonesia has been primarily used for searching for text, some aforementioned keywords also generated nonIndonesian language results, namely energi biomassa and biomassa. This is because energi and/or biomassa terms can also be found in the Swedish and Finnish languages which are similar languages to one another, as well as in Portuguese, Dutch, and Italian.

The list of websites including its uniform resource locator (URL) containing text, which has been included for further readability analysis is presented in Table 4.

Although nineteen Indonesian texts were measured by each readability formula, the authors found that text number eighteen could not be retrieved all of a sudden due to its removal by the website owner. The owner, Sky Energy Indonesia - a joint venture established in 2008 with Hitachi High Technologies Corporation Japan, chose to update its latest website to English only. At the time of text selection from website links found by Google's search engine at the beginning of this study, the URL of text number eighteen as listed in Table 4 was available. It was the introduction of renewable energy written in the Indonesian language. Currently, the introduction is only available in English in the new URL (http//sky-energy.co.id/renewableenergy/). Its previous Indonesian translation was exactly the same as the text retrieved and measured for this study.

Regarding the website publisher in which the text belongs, text number eighteen was the only text listed in this study to be published by the business sector. Most of the texts listed were published by the community as well as individual owners while only one text had its root URL in a university domain as shown in Table 5. This university specializes in agriculture including the technology involved in that discipline. Only two texts found in the root URL were owned by two different government bodies, the Indonesian Agency for the Assessment and Application of Technology (known as Badan Pengkajian dan Penerapan Teknologi (BPPT) in Indonesian) and the Ministry of Energy and Mineral Resources of the Republic of Indonesia (in short ESDM RI).

The results of the readability index for the three originally Englishbased formulas including the indicators used in the formula are presented in Table 6. For the Djoko Formula result, Table 7 presents it along with the used indicators for the calculation of the formula. Each column in Table 7 represents the indicator of the calculation. The number in parentheses is the score of each text that indicates the level of difficulty of each indicator as shown in Table 3.

All indices indicate that all of the information on biomass renewable energy in Bahasa Indonesia is still too difficult to comprehend. Given the SMOG index and the corresponding educational level in the United States' education system as well as some examples of reading material in each SMOG index as mentioned by Taylor [16], all of the information coded in this study can be reached by those who are educated to either a college, or university level, including postgraduates. The same education level was also needed in order to comprehend articles in the Harvard Business Review as well as the USA's Tax Law regulations.

For the Gunning Fog and Flesch-Kincaid measurement on the biomass renewable energy information in Bahasa Indonesia available on the internet, the minimum result is still above the highest level of the index range, which represents its difficulty to read. Both the Gunning Fog and Flesch-Kincaid have a score type which is similar to the SMOG index too, which indicates the level of education needed to understand the text. Given the qualities assessed by SMOG, Gunning Fog, and Flesch-Kincaid measurement are word lengths and sentence lengths, the Djoko Formula uses the number of difficult words and sentences as its parameter, which influences whether a text is easy or difficult to comprehend.

Table 4

List of website URL containing texts measured for readability.

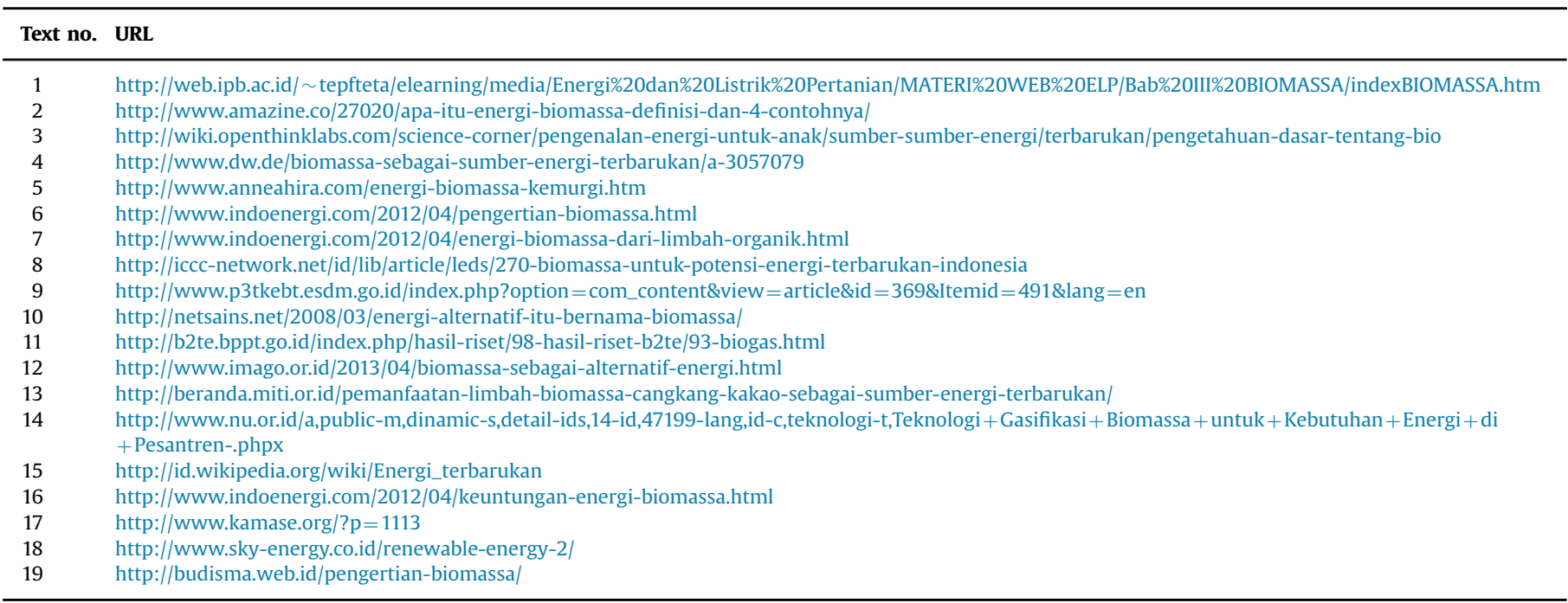


In Table 7, based on the indicator of the average number of paragraphs (column number one), the average score was 2.5 points indicating the average texts observed in this study were in the uppermedium level of difficulty. It designated the level as more than medium, but less than hard. Too much information indicated by the number of paragraphs in the text might also require a higher level of education in order to understand it. From the indicator of average number of sentences per paragraph, the average score was 2.8 indicating that the average texts measured were in the medium level, and almost reached a hard level of reading difficulty. According to the indicator, a text is considered as easy to comprehend if the number of sentences per paragraph are not too small since too few sentences in a paragraph makes it difficult to explain a certain topic being discussed in that paragraph. Given the common stereotypes of engineers and scientists who are perceived as having poor communication skills [33], creating explanatory sentences which are neither too short nor too wordy, but clear for a certain topic within a paragraph was probably not an easy matter. Two indicators mentioned above, which are the average number of paragraphs and the average number of sentences per paragraph were categorized as indicators of a paragraph.

The aforementioned stereotype was also relevant for the indicators of the average number of words per sentence (average length of a sentence) although the difficulty criterion was opposite to the sentence per paragraph indicator. Based on the criteria of sentence length, a sentence whose words were less was easier to comprehend than a longer one. The average score in this criterion was 3 indicating that all of the texts were difficult to read due to the lengths of the sentences. The challenge in this criterion was how to make simple, concise, non-wordy sentences whose message can be clearly conveyed.

Criterion number four was based on the percentage of sentences containing extension words, which is a word that has an extended meaning besides its definite core meaning. For example, the term "sailing (berlayar, in the Indonesian language)" designates any activity that moves across the sea by ship, which is not only a ship with a sail (a sailboat), but also any type of ship although the term initially meant only an activity using a sailboat. The word "sailing" in Bahasa Indonesia is then considered to be extended from its initial or original meaning. The more extension sentences found within a text, the more difficult the text was to comprehend. The average score of this criterion was 1 point indicating that all of the text observed was easy to understand based on the percentage of extension sentences.

Criterion number five was based on the percentage of compound sentences in each text. A compound sentence is a sentence

Table 5

Website publisher and its category in which texts have been measured for readability.

\begin{tabular}{|c|c|c|c|}
\hline Text no. & Website publisher & Root URL & Publisher category \\
\hline 1 & Bogor Agriculture University & ipb.ac.id & University \\
\hline 2 & Amazine - Online Popular Knowledge Portal & amazine.co & Community \\
\hline 3 & OpenThink Labs - Online Knowledge Portal & openthinklabs.com & Community \\
\hline 4 & Deutsche Welle - in the Indonesian Language & dw.de & Government Agency \\
\hline 5 & Anne Ahira for Indonesia & anneahira.com & Individual \\
\hline $6,7,16$ & Indoenergi & indoenergi.com & Community \\
\hline 8 & Indonesia Climate Change Center & iccc-network.net & Government Agency \\
\hline 9 & Energy and Mineral Resources R\&D Board & p3tkebt.esdm.go.id & Government R \& D \\
\hline 10 & Netsains - Online Knowledge Portal & netsains.net & Community \\
\hline 11 & Energy Technologies Laboratory & b2te.bppt.go.id & Government R \& D \\
\hline 12 & Bojonegoro Student Association & imago.or.id & Community \\
\hline 13 & Community of Indonesian Scientists & beranda.miti.or.id & Community \\
\hline 14 & Nahdlatul Ulama & nu.or.id & Community \\
\hline 15 & Wikipedia & id.wikipedia.org & Community \\
\hline 17 & Student Community of Energy Center & kamase.org & Community \\
\hline 18 & Sky Energy & sky-energy.co.id & Business \\
\hline 19 & Budisma & budisma-web.id & Individual \\
\hline
\end{tabular}

Table 6

Texts and readability indicators for SMOG, Gunning Fog, and Flesch-Kincaid Formulas.

\begin{tabular}{|c|c|c|c|c|c|c|c|c|c|}
\hline \multirow[t]{2}{*}{ Text no. } & \multicolumn{3}{|l|}{ Number of } & \multicolumn{3}{|l|}{ Average number of } & \multirow[t]{2}{*}{ SMOG index } & \multirow[t]{2}{*}{ Gunning Fog index } & \multirow[t]{2}{*}{ Flesch-Kincaid index } \\
\hline & Sentences & Words & Characters & Words/sentences & Syllables/words & Characters/words & & & \\
\hline 1 & 75 & 1274 & 8037 & 17 & 2.7 & 6.2 & 16.2 & 25.2 & 21.4 \\
\hline 2 & 29 & 418 & 2669 & 14 & 3 & 6.4 & 15.4 & 24.9 & 20.8 \\
\hline 3 & 37 & 565 & 3285 & 15 & 2 & 5.8 & 14.7 & 22 & 18.6 \\
\hline 4 & 26 & 337 & 2062 & 13 & 3 & 6.1 & 13.8 & 22.9 & 19.4 \\
\hline 5 & 57 & 1011 & 6250 & 18 & 3 & 6.2 & 16.2 & 24.2 & 21.4 \\
\hline 6 & 14 & 259 & 1568 & 19 & 3 & 6.1 & 16.6 & 24.7 & 21.4 \\
\hline 7 & 29 & 531 & 3254 & 18 & 3 & 6.1 & 16.2 & 24.3 & 21.1 \\
\hline 8 & 35 & 549 & 3333 & 16 & 3 & 6.1 & 15.2 & 22.7 & 20.3 \\
\hline 9 & 16 & 297 & 1791 & 19 & 3 & 6 & 17.5 & 26.7 & 21.7 \\
\hline 10 & 57 & 1005 & 6309 & 18 & 2.7 & 6.3 & 16.3 & 25 & 21 \\
\hline 11 & 9 & 211 & 1333 & 23 & 2 & 6.3 & 18.4 & 25.7 & 22.6 \\
\hline 12 & 37 & 534 & 3381 & 14 & 3 & 6.3 & 15.3 & 24.6 & 21 \\
\hline 13 & 43 & 869 & 5414 & 20.5 & 3 & 6.3 & 17.7 & 25 & 22.6 \\
\hline 14 & 38 & 723 & 4576 & 19.5 & 2.5 & 6.3 & 17.1 & 25.1 & 22 \\
\hline 15 & 22 & 447 & 2829 & 20 & 3 & 6.3 & 17.7 & 26.7 & 22.8 \\
\hline 16 & 29 & 479 & 2933 & 17 & 3 & 6.3 & 15.3 & 23.6 & 20.7 \\
\hline 17 & 52 & 973 & 5917 & 18.7 & 2.3 & 6.1 & 16.1 & 23.7 & 20.9 \\
\hline 18 & 17 & 435 & 2565 & 26 & 2 & 5.9 & 19.2 & 26.6 & 23.1 \\
\hline 19 & 27 & 450 & 2831 & 17 & 3 & 6.3 & 16.4 & 25.2 & 21.4 \\
\hline
\end{tabular}


Table 7

Readability indicators and the score of each text for the Djoko Formula.

\begin{tabular}{|c|c|c|c|c|c|c|c|c|c|c|c|c|c|}
\hline \multirow[t]{2}{*}{ Text no. } & \multicolumn{2}{|c|}{ Paragraph indicators } & \multicolumn{5}{|c|}{ Sentence indicators } & \multicolumn{6}{|c|}{ Word indicators } \\
\hline & 1 & 2 & 3 & 4 & 5 & 6 & 7 & 8 & 9 & 10 & 11 & 12 & 13 \\
\hline 1 & $22(3)$ & $3.4(3)$ & $17(3)$ & $57.3(1)$ & $94.7(3)$ & $1.3(3)$ & $60(3)$ & $0(1)$ & $0.2(1)$ & $12.5(3)$ & $13.5(3)$ & $7.9(3)$ & $2(1)$ \\
\hline 2 & $7(3)$ & $4.1(3)$ & $14.4(3)$ & $62.1(1)$ & $100(3)$ & $0(3)$ & $79.3(3)$ & $0.24(1)$ & $4.8(1)$ & $5.7(2)$ & $13.6(3)$ & $2.4(1)$ & $3.3(2)$ \\
\hline 3 & $7(3)$ & $5.3(2)$ & $15.3(3)$ & $59.5(1)$ & $81.1(3)$ & $0(3)$ & $45.9(3)$ & $0(1)$ & $1.1(1)$ & $4.8(1)$ & $12.9(3)$ & $11.5(3)$ & $2.1(1)$ \\
\hline 4 & $6(2)$ & $4.3(3)$ & $13(3)$ & $26.9(1)$ & $65.4(3)$ & $7.7(3)$ & $57.7(3)$ & $0(1)$ & $0.9(1)$ & $5.6(2)$ & $10.7(3)$ & $7.4(3)$ & $3.3(2)$ \\
\hline 5 & $13(3)$ & $4.4(3)$ & $17.7(3)$ & $43.9(1)$ & $94.7(3)$ & $0(3)$ & $49.1(3)$ & $0.3(1)$ & $1.1(1)$ & $5.7(2)$ & $10.9(3)$ & $11.5(3)$ & $2.4(1)$ \\
\hline 6 & $4(1)$ & $3.5(3)$ & $18.5(3)$ & $57.1(1)$ & $92.9(3)$ & $7.1(3)$ & $64.3(3)$ & $0(1)$ & $0(1)$ & $10.4(3)$ & $9.3(3)$ & $9.3(3)$ & $2.7(1)$ \\
\hline 7 & $10(3)$ & $2.9(3)$ & $18.3(3)$ & $41.4(1)$ & $93.1(3)$ & $0(3)$ & $41.4(3)$ & $0.4(1)$ & $0.8(1)$ & $4.1(1)$ & 10.9 (3) & $10(3)$ & $3.6(2)$ \\
\hline 8 & $9(3)$ & $3.9(3)$ & $15.7(3)$ & $51.4(1)$ & $80(3)$ & $2.9(3)$ & $54.3(3)$ & $0.2(1)$ & $0.5(1)$ & $6.6(2)$ & $10.6(3)$ & $12.2(3)$ & $4.2(3)$ \\
\hline 9 & $3(1)$ & $5.3(2)$ & $18.6(3)$ & $68.8(1)$ & $75(3)$ & $0(3)$ & $50(3)$ & $0.3(1)$ & $1(1)$ & $13.5(3)$ & $12.5(3)$ & $16.8(3)$ & $2(1)$ \\
\hline 10 & $14(3)$ & $4.1(3)$ & $17.6(3)$ & $54.4(1)$ & $87.7(3)$ & $0(3)$ & $49.1(3)$ & $0.3(1)$ & $1.7(1)$ & $6.7(2)$ & $12.2(3)$ & $14(3)$ & $1.2(1)$ \\
\hline 11 & $5(1)$ & $1.8(3)$ & $23.4(3)$ & $55.6(1)$ & $100(3)$ & $0(3)$ & $55.6(3)$ & $0(1)$ & $2.8(1)$ & $9(3)$ & $12.3(3)$ & $16.1(3)$ & $3.3(2)$ \\
\hline 12 & $6(2)$ & $6.2(1)$ & $14.4(3)$ & $43.2(1)$ & $70.3(3)$ & $0(3)$ & $59.5(3)$ & $0.4(1)$ & $2.4(1)$ & $5.8(2)$ & $11(3)$ & $12.9(3)$ & $1.5(1)$ \\
\hline 13 & $10(3)$ & $4.3(3)$ & $20.2(3)$ & $51.2(1)$ & $83.7(3)$ & $0(3)$ & $81.4(3)$ & $0.1(1)$ & $1.8(1)$ & $6(2)$ & $11.2(3)$ & $17.7(3)$ & $1.7(1)$ \\
\hline 14 & $10(3)$ & $3.8(3)$ & $19(3)$ & $52.6(1)$ & $97.4(3)$ & $0(3)$ & $50(3)$ & $0.1(1)$ & $0(1)$ & $8(2)$ & $10.8(3)$ & $10.1(3)$ & $1.8(1)$ \\
\hline 15 & $8(3)$ & $2.8(3)$ & $20.3(3)$ & $63.6(1)$ & $100(3)$ & $0(3)$ & $63.6(3)$ & $0(1)$ & $0.5(1)$ & $8.1(2)$ & $15.7(3)$ & $8.5(3)$ & $2.7(1)$ \\
\hline 16 & $8(3)$ & $3.6(3)$ & $16.5(3)$ & $37.9(1)$ & $100(3)$ & $0(3)$ & $72.4(3)$ & $0(1)$ & $0(1)$ & $5.8(2)$ & $12.9(3)$ & $10.2(3)$ & $2.3(1)$ \\
\hline 17 & $14(3)$ & $3.7(3)$ & $18.7(3)$ & $46.2(1)$ & $46.2(2)$ & $0(3)$ & $50(3)$ & $0.2(1)$ & $3.3(1)$ & $2.1(1)$ & $11.8(3)$ & $10.7(3)$ & $2.9(1)$ \\
\hline 18 & $4(1)$ & $4.3(3)$ & $25.6(3)$ & $64.7(1)$ & $94.1(3)$ & $0(3)$ & $94.1(3)$ & $0.2(1)$ & $1.4(1)$ & $2.5(1)$ & $8.5(3)$ & $13.3(3)$ & $3.9(2)$ \\
\hline 19 & $7(3)$ & $3.9(3)$ & $16.7(3)$ & $33.3(1)$ & $88.9(3)$ & $0(3)$ & $55.6(3)$ & $0(1)$ & $0.2(1)$ & $8.9(3)$ & $14.7(3)$ & $15.3(3)$ & $1.6(1)$ \\
\hline
\end{tabular}

with more than one subject or predicate. The average score of this criterion was 2.9 points indicating that the entire text observed was hard to understand. This criterion challenged an author of renewable energy information on the internet to consider creating expressions simply by using one subject and one predicate within a sentence so that the sentence would be more understandable.

Criterion number six was based on the percentage of sentences with polysemy in each text. Polysemy is a word with more than one meaning. This criterion contributes 3 points on average of the whole text observed. From the percentage of passive sentence criterion, the average score was 3 points indicating that all of the text was difficult to understand due to the high-portion of passive sentences within a text.

Based on the indicator of words, which consists of the percentage of unfamiliar words, abstract words, terms, conjunctions, loan words, and phrases, the average scores of each indicator showed that the texts were relatively easy to understand compared with that of paragraph indicators as well as sentence indicators. The criteria of both unfamiliar words and abstract words contributed to 1 point of the average readability score indicating that all of the text was easy to understand regardless of the percentage of unfamiliar and abstract words contained in the text. Although the percentage of phrases contributed to more than 1 point of the average readability score, it was less than 2 points, which indicated that the texts were still considered as easy to understand based on the percentage of phrases used in a text. Both criteria on the percentage of loan words and terms indicated that the observed texts were at the medium level of readability represented by 2.9 points and 2.1 points, respectively of the average readability scores. The average score on the loan words criteria was a bit higher compared with the other criteria among the word indicators. The use of loan words was unavoidable in order to explain biomass renewable energy because of the original scientific terms. However, the lower the usage of loan words made a text easier to comprehend. The only difficulty in the word criteria point of view was contributed by the percentage of conjunctions found in a text. The percentage contributed 3 points of the average score indicating the overall text was difficult to comprehend based on how many conjunctions were used in a text.

This study has limitations since an analysis solely based on readability indices cannot fully justify whether or not information readability requires a certain level of education due to the differences in ways of explanation in the Indonesian language from that in English.
However, as DuBay mentioned in his comprehensive review on readability studies [34] that due to the limitations of readability formulae, readability researchers have recommended that formulae are best used in conjunction with other methods. Basically, readability can be determined by using two methods; the readability formula and reader responses [35]. Readability formulae are instruments to predict the difficulty in reading a text while reader responses are a set of tests on the ability to read a text. Therefore, this readability study emphasizes the prediction of difficulty in reading renewable energy information. By predicting how difficult a text is that explains renewable energy issues, the issues then could be relatively well prepared in terms of their readability before their interaction with the general public.

Given the nature of academics and scientists, industries, and policy makers on renewable energy who are not specialists in linguistics, performing both readability formulae and reader response methods would take an extremely long time. This nature may create more separation between the general public and academics/scientists as well as industries and policy makers on renewable energy. This bold line may be dealt with by middle actors such as communicator specialists, who serve as consultants in the implementation of technology including renewable energy. The utilization of readability formulae by academics and scientists, industries, and policy makers would not only attract them to engage with the general public as a key to the successful implementation of technology, but also then make them communicators, although less specialized, who are also experts in renewable energy technologies. As the available formulae are ready to use, the less specialized persons who are not necessarily linguists might be able to measure the readability of texts. As far as he/she has basic linguistic skills, which are the ability to distinguish characters in words, syllables in words, words in sentences, and sentences in paragraphs, he/she can measure the readability of texts. However, this is especially applicable for English-based formulae due to their aforementioned readability indicators. For Indonesian-based formulae, a little training is needed since its indicators are more than that of those which are English-based as shown in Table 3.

The limitations due to the different ways of explanation in the Indonesian language from those in English, have also been implicitly mentioned in DuBay's review [34]. DuBay highlighted the discrepancy between the scores of different readability formulae, which have long been confusing. This discrepancy has been caused by different variables, which are used by different formulae and consequently by 
different criteria for measuring the readability. The review gave an example; a formula uses $75 \%$ of correct answers to predict a certain level of a readability score while another formula uses $50 \%$ of correct answers to predict the same level of a readability score. The other formula may predict the same level of readability by only answering $65 \%$ correctly. DuBay finally mentioned clearly in the review that the range of readability scores or levels resulting from different readability formulae "remind us that they are not perfect predictors. They provide probability statements, or, rather, rough estimates of text difficulty. That means the readability formulae account for 50-84 percent of the variance in the text difficulty as measured by comprehension tests". (Page 56).

Therefore, different corresponding vocabularies between English and Indonesian as aforementioned that leads to different score of indices is in line with the explanation above. For the information, DuBay noted that an English-based readability formula has been utilized for 12 languages including the Malay language, which is virtually identical to the Indonesian language [16].

\section{Conclusion and recommendation}

This study has brought to light the utilization of readability measurements in the improvement of the general public's understanding of renewable energy especially biomass energy technology. Among ten of the most well known English-based readability measurement methods, this study selected Flesch-Kincaid, Gunning-Fog, and SMOG indices since they are mostly found in the most recent literature on readability studies. Since the measured texts were in the Indonesian language, this study also chose the Djoko Formula as an original readability method for the Indonesian language (Bahasa Indonesia). Compared to English-based readability methods, to the author's knowledge, the Djoko Formula is the only readability formula that has been specifically developed for the Indonesian language. Different with that of English-based methods whose readability variables are only characters, syllables, words, sentences, and paragraphs, the Djoko Formula has thirteen indicators for measuring readability.

It was found that the word indicators did not really contribute to the difficulty of biomass energy reading comprehension in Bahasa Indonesia on the internet in spite of the origin of the technologies' terms coming from another language. Many English technical terms were unavoidable when addressing renewable energy technology from biomass. Therefore, it is also important for scientists and engineers working on biomass energy technology to engage with the general public more frequently in order to disseminate biomass energy information more effectively. By improving the general public's engagement in the work of the scientists and engineers who specialize in biomass energy, the reliability of information on biomass technology can be maintained. This needs to be conducted so as to avoid any misunderstandings of the technology that, in turn, would lead to barriers in the implementation of biomass technology.

A study on the readability of biomass information using the readability formulae includes a weakness. Since the formulae depend on the number of paragraphs, sentences, words, and syllables including their comparison with their parameters, they may not accurately reflect the understandability of the reading. Therefore, measuring the readability level does not depend only on the readability formula, but also on the readers' responses. Since this study used only readability formulae, it emphasized the prediction of difficulty in reading biomass energy information. Furthermore, given the nature of academics and scientists, including industries and policy makers on biomass energy technologies who are not specialists in linguistics, performing both the readability formula and reader responses methods would be time and money consuming.

According to the website search results, this study found that biomass energy information which is reliable, high-quality, as well as easy to read is still quite limited. Therefore, more biomass renewable energy information in Bahasa Indonesia should be created and published on the internet by carefully considering the readability indicators in order to make the information easy to comprehend. This consequently means that universities and research agencies as well as government bodies should play more of a key role in the dissemination of biomass renewable energy information that is available on the internet.

\section{Acknowledgment}

This study was supported financially by JSPS KAKENHI Grant number $15 \mathrm{H} 05228$. The authors greatly appreciate the support.

\section{References}

[1] Liu W, Wang C, Mol APJ. Rural public acceptance of renewable energy deployment: the case of Shandong in China. Appl Energy 2013;102:1187-96.

[2] Sovacool BK, Ratan P Lakshmi. Conceptualizing the acceptance of wind and solar electricity. Renew Sustain Energy Rev 2012;16(7):5268-79.

[3] Molin E. Causal analysis of hydrogen acceptance. Jan. Transp Res Rec 2005:1941(1):115-21.

[4] Achterberg P, Houtman D, van Bohemen S, Manevska K. Unknowing but supportive? Predispositions, knowledge, and support for hydrogen technology in The Netherlands Jun. Int J Hydrog Energy 2010;35(12):6075-83.

[5] O'Garra T, Mourato S, Pearson P. Investigating attitudes to hydrogen refuelling facilities and the social cost to local residents. Jun. Energy Policy 2008;36 (6):2074-85

[6] Duan $\mathrm{H}$. The public perspective of carbon capture and storage for $\mathrm{CO}_{2}$ emission reductions in China. Sep. Energy Policy 2010;38(9):5281-9.

[7] Hasan MH, Mahlia TMI, Nur H. A review on energy scenario and sustainable energy in Indonesia. May. Renew Sustain Energy Rev 2012;16(4):2316-28.

[8] Abu Bakar AS, Ameer R. Readability of corporate social responsibility communication in Malaysia. Jan. Corp Soc Responsib Environ Manag 2011;18 (1):50-60.

[9] FAOSTAT. [Online]. Available: 〈http://faostat3.fao.org/〉; [accessed 23.09.14].

[10] Stigka EK, Paravantis J a, Mihalakakou GK. Social acceptance of renewable energy sources: a review of contingent valuation applications. Renew Sustain Energy Rev 2014;32:100-6.

[11] Sovacool BK. Rejecting renewables: the socio-technical impediments to renewable electricity in the United States. Nov. Energy Policy 2009;37 (11):4500-13.

[12] Le Lim X, Lam WH. Public acceptance of marine renewable energy in Malaysia. Energy Policy 2014;65:16-26.

[13] Luthra S, Kumar S, Garg D, Haleem A. Barriers to renewable/sustainable energy technologies adoption: indian perspective. Renew Sustain Energy Rev 2015; $41: 762-76$

[14] Indonesia Internet Users-Internet Live Stats. [Online]. Available: 〈〈http://www. internetlivestats.com/internet-users/indonesia/ $\rangle\rangle$; [accessed 16.08.15].

[15] A.P.J.I. Indonesia, Indonesia internet user profile 2014 (in Indonesian). [Online]. Available: 〈http://www.apjii.or.id/v2/upload/statistik/Survey APIII 2014 v3. pdf); 2015 [accessed 05.08.15].

[16] Taylor G. Readability of OHS documents - a comparison of surface characteristics of OHS text between some languages. Aug. Saf Sci 2012:50(7):1627-35.

[17] Shepperd S, Charnock D, Gann B. Helping patients access high quality health information. Oct. BMJ 1999;319(7212):764-6

[18] Jayaratne YSN, Anderson NK, Zwahlen RA. Readability of websites containing information on dental implants. Oct. Clin Oral Implants Res 2013.

[19] Hendrick PA, Ahmed OH, Bankier SS, Chan TJ, Crawford SA, Ryder CR, Welsh LJ, Schneiders AG. Acute low back pain information online: an evaluation of quality, content accuracy and readability of related websites. Man Ther 2012;17(4):318-24.

[20] Grewal P, Alagaratnam S. The quality and readability of colorectal cancer information on the internet. Int I Surg 2013:11(5):410-3.

[21] Vargas CR, Chuang DJ, Ganor O, Lee BT. Readability of online patient resources for the operative treatment of breast cancer. Aug. Surgery 2014;156(2):311-8.

[22] Li F. Annual report readability, current earnings, and earnings persistence. Aug. I Account Econ 2008:45(no. 2-3):221-47.

[23] Howes LM, Julian R, Kelty SF, Kemp N, Kirkbride KP. The readability of expert reports for non-scientist report-users: reports of DNA analysis. Apr. Forensic Sci Int 2014;237:7-18.

[24] Mavasoglu M, Dincer S. Readability and french language teaching texts: an analysis of french language teaching websites and textbooks. Feb. ProcediaSoc Behav Sci 2014;116:256-9.

[25] Putra RMS. Fog index dan keterbacaan berita utama (Headline) suara merdeka 03 Mei 2013. J Ilmu Komun 2013;10(1):41-8. 
[26] Dempsey SJ, Harrison DM, Luchtenberg KF, Seiler MJ. Financial opacity and firm performance: the readability of REIT annual reports. J Real Estate Financ Econ 2012;45(2):450-70.

[27] Free readability formulas : free readability tools : readability software. [Online]. Available: 〈http://readabilityformulas.com/〉; 2014 [accessed 30.03.14].

[28] Pranowo DD. Alat ukur keterbacaan teks berbahasa Indonesia. (thesis in Indonesian). Yogyakarta State University; 1998 http://staff.uny.ac.id/sites/ default/files/131764502/Artikel\%20TESIS\%20S2\%20JOKO.pdf.

[29] Lee CS, Ma L. News sharing in social media: the effect of gratifications and prior experience. Mar. Comput Human Behav 2012;28(2):331-9.

[30] Hsu C-L, Lin JC-C. Acceptance of blog usage: the roles of technology acceptance, social influence and knowledge sharing motivation. Jan. Inf Manag 2008;45(1):65-74.

[31] Dunne Á, Lawlor M, Rowley J. Young people's use of online social networking sites - a uses and gratifications perspective. J Res Interact Mark 2010;4:46-58.
[32] Park N, Kee KF, Valenzuela S. Being immersed in social networking environment: facebook groups, uses and gratifications, and social outcomes. Dec. Cyberpsychol Behav 2009;12(6):729-33.

[33] Hankins N. Communication skills for engineers and scientists. ISBN: 085295 455 7. In: Venables John, editor. Process Safety and Environmental Protection, 80. IChemE; 2002. p. 2002 http://www.sciencedirect.com/science/article/ pii/S0957582002710495, http://dx.doi.org/10.1205/095758202762277650.

[34] DuBay WH. The principles of readability. 2004.

[35] Singer H, Donlan D. Active comprehension: problem-solving schema with question generation for comprehension of complex short stories. Read Res Q $1982 ; 17(2): 166-86$ 